\section{Faith, hope and objectives}

\author{
Stephen Hancocks OBE \\ Editor-in-Chief
}

Send your comments to the

Editor-in-Chief,

British Dental Journal

64 Wimpole Street,

London

W1G 8YS

Email bdj@bda.org
The title jars rather doesn't it? We are much more familiar with the flowing and comforting phrase from childhood which runs as 'faith hope and charity, the greatest of these being charity'. In all walks of life the giving of charity in whatever forms that might take, money, resources, time, physical exertion, intellectual capacity or experience, implies a good act and a positive deed. To be confronted therefore with a question mark over the veracity of one's contribution, indeed to be informed that the selfless action may not only do no good but possibly create harm, is a bitter and self-affronting experience indeed.

Yet if we are to understand correctly the article by Holmgren and Benzian in this issue, ${ }^{1}$ these are real concerns that can stem from some current forms of dental volunteering overseas. The debate is well represented in the article, which I urge you to read, but the occasion for raising the subject was generated by a group of individuals representing some of the leading dental charities in the UK and elsewhere who organised a forum at the British Dental Conference last month with the help of the BDA.

\section{NOT RANDOM GOOD DEEDS BUT BETTER CO-ORDINATION}

The purpose of the forum was to raise awareness that the traditional model of dental volunteering may no longer be appropriate in a world which needs to progress from the unquestionably worthy and laudable but somewhat random good deeds by well meaning individuals to a better organised and, by definition, a more effective use of the resources offered for the benefit of those in receipt.

What needs to be made clear is that no criticism is being levelled at those who volunteer in the desire to help those less fortunate in terms of oral healthcare. On the contrary, none of this can reasonably be achieved in the future without such open generosity. What is at the heart of the matter is a discussion about the best way in which appropriate help can be accomplished. This may involve calls for professionals with skills which range from clinical, to public health, to education and even to political advocacy, since the sustainability of good oral health as initiated by volunteers will inevitably require effects that last long after they have returned home.

Interestingly, some in the field are now making links between volunteerism which may be deemed to be benefiting the volunteer disproportionately in comparison to the recipient and the seeking of healthcare oversees for reasons of lower costs or jumping queues in countries in which health spending is either restricted or in which waiting lists exist. ${ }^{2}$ Terming these voluntourism and medical tourism, the questions raised revolve around whether resources in the wealthier nations should be better organised and allocated and whether those resources sought and consumed by medical tourists in poorer nations should actually be used to treat indigenous patients instead. Whether this strengthens our understanding of the specific matters concerned with the effectiveness of charitable activities or serves only as a muddying of waters and a worthy but complex distraction depends on one's point of view, but what it does serve to do is highlight the inter-relation of oral health and oral healthcare in a global society.

Quite how the matter of making charities more effective might be achieved is a question yet to be answered. It seems unlikely that a single organisation, body or association is equipped or, arguably, appropriate to take over such a role. By their nature, charities and charitable acts often have their foundations in individual motivations and in personal circumstances based on desire to help and on kindness in the face of adversity. Any attempt to institutionalise these human actions is likely not only to be misunderstood but to be studiously avoided as a possible additional barrier or interference in the way of 'our' charity. What seems to be emerging as a more pragmatic solution is the development and eventual adoption of a voluntary code of ethical actions based on the needs not only of those to whom the charity is offered but in the training and preparation of those offering their time and skills.

This will no doubt be achieved by the growth of strategic partnerships between charities, non-governmental organisations and others in building consensus on appropriate care, which will almost certainly be based on the three elements of the Basic Package of Oral Care. ${ }^{3}$ The hope must surely be that with faith in our ability as a caring profession to not only provide care but to organise it in such as way that it delivers maximum effectiveness, then charity which begins at home can also extend to oral health improvement far and wide.

1. Holmgren $C$, Benzian $H$. Dental volunteering - a time for reflection and a time for change. Br Dent J 2011; 210: 513-516.

2. Synder J, Dharamsi S, Crooks A. Fly-by medical care: conceptualizing the global and local social responsibilities of medical tourism and physician voluntourists. Global Health 2011; 7: 6-19.

3. Benzian H, van Palenstein-Helderman W. Dental charity work - does it really help? Br Dent J 2006; 201: 413 